EISSN:2706-7920 ISSN: 2077-4435

DOI: $10.36632 /$ csi/2021.10.2.23

Journal homepage: www.curresweb.com

Pages: 242-252

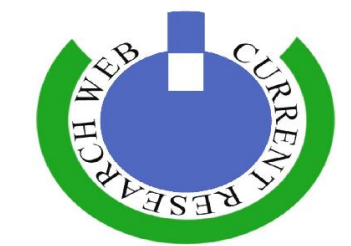

\title{
Antifibrotic Effects of Quercetin and Adenosine Deaminase Inhibitor on Thioacetamide-Induced Liver Fibrosis Mediated By P53 and NF-Kß Gene Expression
}

\author{
Marwa A. Magdy ${ }^{1}$, Hossam El-Din M. Omar ${ }^{2}$, Sary Kh. Abdel-Ghaffar ${ }^{3}$ and Ahmed Th. \\ Ibrahim $^{1}$
}

${ }^{1}$ Department of Zoology, Faculty of Science, New Valley University, New Valley, Egypt.

${ }^{2}$ Department of Zoology, Faculty of Science, Assiut University, Assiut, Egypt.

3 Department of Pathology and Clinical Pathology, Faculty of Veterinary of Medicine, Assiut University, Assiut, Egypt.

Received: 25 February $2021 \quad$ Accepted: 05 April 2021

Published: 15 April 2021

\begin{abstract}
Potent hepatotoxic chemicals such as thioacetamide (TAA) are used to evaluate hepatoprotective agents. Here we investigate the antifibrotic potential of quercetin (QU) as antioxidant and Erythro-9(2-hydroxy-3-nonyl) adenine (EHNA) as adenosine deaminase inhibitor against thioacetamide- induced liver fibrosis in male rats. Fifty mature male rats divided into 5 groups: Group I: served as a control was intraperitoneally (IP) injected with Dimethyl sulfoxide (DMSO) by $0.5 \mathrm{ml} /$ rat. Group II: rats were injected IP with TAA ( $200 \mathrm{mg} / \mathrm{kg}$ ) twice a week for 3 months. Group III: rats were injected IP with QU $(100 \mathrm{mg} / \mathrm{kg}) 30 \mathrm{~min}$ before TAA injection Group IV: rats were injected IP with EHNA $(150 \mu \mathrm{M} / \mathrm{kg}) 30$ min before TAA injection. Group V: rats were injected IP with QU (100 mg/kg) and EHNA (150 $\mu \mathrm{M} / \mathrm{kg}$ ) $30 \mathrm{~min}$ before TAA injection. TAA administration causes hepatic necrosis, increases in liver function enzymes, increases in hepatic lipid peroxidation, decrease in glutathione level and increase in the gene expression of tumor protein (P53) and Nuclear Factor-kappa Beta (NF-k $\beta$ ). With administration of QU alone, EHNA alone or the combination of both significantly attenuated liver fibrosis induced by TAA through decrease of liver biomarkers, improving the redox state of the tissue as well as hindered the expression of inflammation and apoptosis-related genes. Finally, it can be concluded that QU alone, EHNA alone or the combination of both have protective effects against TAA-induced hepatic fibrosis.
\end{abstract}

Keywords: Thioacetamide; Quercetin; adenosine deaminase inhibitor; fibrosis

\section{Introduction}

The liver is the largest vital organ that plays an important role in metabolism and detoxification events (Kaur et al., 2017). Many causative agents that lead to chronic liver damage includes viral hepatitis $\mathrm{B}$ and $\mathrm{C}$ infections, radiation and alcohol abuse causes liver lobule necrosis, cirrhosis (Friedman, 2000), preneoplastic lesions (Zargar et al., 2017), biliary duct proliferation and multiple sites of cholangiocarcinoma with stromal desmoplasia as seen in humans and rodents (Seki et al., 2009).

Thioacetamide (TAA) as a source of hydrogen sulfide to precipitate metal sulfides is a severe hepatotoxic agent that causes liver fibrosis (Kadir et al., 2011), cirrhosis and liver cancer (De Minicis et al., 2013). TAA is a white crystalline solid, soluble in water and alcohol used in leather processing, laboratories and as a stabilizer of motor fuels (Lee et al., 2003). Liver cytochrome (Cyt-P450) transforms TAA to thioacetamide S-oxide (TAASO) and then to thioacetamide S,S-dioxide (TAASO2) (Amali et al., 2006). TAASO caused enlargement of nucleoli, change in cell permeability, and inhibited the activity of mitochondrial (Gupta and Dixit, 2009; Prabha et al., 2012), whereas, TASSO2 enhanced biomarkers of tissue necrosis and inflammation such as (inducible Nitric Oxide Synthase) iNOS and (Nuclear Factor-kappa Beta) NF-k $\beta$ (Chen et al., 2008). Accordingly, inflammation and necrosis of liver tissue were observed one week after a single injection of TAA (Luo et al., 2015). Oxidative stress 
is known to be involved in the TAA induced chronic and metabolic liver disease (Li et al., 2015). In chronic liver diseases and fibrosis, administration of antioxidants may ameliorate or prevent this condition (Casas-Grajales and Muriel, 2015).

Quercetin (QU) is one of the most common flavonoids which is found in fruits and vegetables such as blueberries, onions and broccoli (Manach et al., 1999). These flavonoids have pharmacological activities as anti-inflammatory, antioxidant ( Tieppo et al., 2009; Granado-Serrano et al., 2012) and immuno-regulatory (Barreca et al., 2016; Eid and Haddad, 2017). The cytoprotective effect of QU may be due to its ability to react with the lipid membrane of the cell, it can decrease the expression of the pro-inflammatory cytokines and down-regulation the activation of NF-k $\beta$. (Madhavan et al., 2006). Moreover, QU exerts strong antitumor activities in vitro and in vivo (Massi et al., 2017) and reduces the risk of oxidative stress in chronic diseases (Wu et al., 2011).

Adenosine deaminase, (ADA), is an important enzyme distributed in all mammalian cells that converts adenosine to inosine irreversibly (Lupidi et al., 1997). It is activity is high in the lymphoid system, brain and gastrointestinal tract (Sauer et al., 2012). Erythro-9-(2-hydroxy-3-nonyl) adenine (EHNA) is a crystalline solid soluble in organic solvents such as ethanol, Dimethyl sulfoxide (DMSO), and dimethylformamide (DMF). Moreover, EHNA keeps the cellular capacity for the deamination of purines so it is less toxic than other ADA inhibitors (Barankiewicz et al., 1997). EHNA prevents adenosine breakdown so it can raise adenosine concentrations that is following its release from cells to the plasma membranes of surrounding cells, where it binds to specific cell surface receptors $\left(A_{1}, A_{2 A}\right.$, $\mathrm{A}_{2 \mathrm{~B}}$, and $\mathrm{A}_{3}$ ) adenosine receptors caused production of either pro-inflammatory or anti-inflammatory effects (Fredholm et al., 2001; Hasko and Cronstein, 2004) and also produce antitumor effects against a variety of cancer cells (Nakajima et al., 2015).

\section{Materials and Methods}

\subsection{Drugs and Chemicals}

Thioacetamide (TAA), Quercetin (QU) and adenosine deaminase inhibitor erythro- 9-(2-hydroxy-3nonyl) adenine (EHNA) were obtained from Sigma Chemical Co. (St. Louis, MO, USA). Kits used for measurement of plasma aspartate transaminase (AST), alanine transaminase (ALT), gamma glutamic transpeptidase (GGT) were purchased from Agappe diagnostics Switzerland, GMBH. and total bilirubin (TB) was purchased from Diamond diagnostic, Egypt. Kits for estimation of hepatic malondialdehyde (MDA) and glutathione (GSH) were purchased from Biodiagnostic, Egypt), (TP53) antibody was obtained from (Santa Cruz Biotechnology, INC) and (NF-k $\beta$ ) antibody was obtained from (Cell Signaling Technology), also the high purity chemicals and reagents were available.

\subsection{Animals}

Fifty adult male albino rats weighting $(120-150 \mathrm{~g})$ were purchased from the animal house of the Faculty of Medicine, Assuit University, Assuit, Egypt. Rats were housed in cages, five rats each and were kept in a room temperature $\left(30 \pm 3^{\circ} \mathrm{C}\right)$ with normal $12 \mathrm{~h}$ light/ $12 \mathrm{~h}$ dark cycle. All of animal procedures were performed in accordance with the guidelines for the care and use of experimental animals established by the Committee for the Purpose of Control and Supervision of Experiments on Animals (CPCSEA) and the protocol of the National Institutes of Health (NIH).

\subsection{Treatment groups}

Animals were divided into 5 groups of 10 animals each. Group I: served as a control was intraperitoneally (IP) injected with (DMSO) by $0.5 \mathrm{ml} / \mathrm{rat}$. Group II: rats were injected IP with TAA $(200 \mathrm{mg} / \mathrm{kg}$ ) twice a week for 3 months (Nazmy et al., 2019). Group III: rats were injected IP with QU $(100 \mathrm{mg} / \mathrm{kg}) 30 \mathrm{~min}$ before TAA injection (El-Nekeety et al., 2014). Group IV: rats were injected IP with EHNA (150 $\mu \mathrm{M} / \mathrm{kg}) 30$ min before TAA injection (Junqueira et al., 2010). Group V: rats were injected IP with QU $(100 \mathrm{mg} / \mathrm{kg})$ and EHNA $(150 \mu \mathrm{M} / \mathrm{kg}) 30 \mathrm{~min}$ before TAA injection.

\subsection{Collection of samples}

Animals of different groups were killed after anesthesia with ether. From the optic nerve the blood was collected into a sterilized tube containing EDTA $(100 \mathrm{mg} / \mathrm{ml})$. For the histological studies, pieces of liver were fixed in $10 \%$ neutral buffered formalin. The liver was quickly removed and washed 
in $100 \mathrm{mM}$ phosphate buffer ( $\mathrm{pH} 7.4)$ and then stored at $-20^{\circ} \mathrm{C}$ for biochemical studies.

\subsection{Tissue and plasma preparation}

$10 \%$ homogenate of the liver was prepared by homogenization of $250 \mathrm{mg}$ of each tissue in 2.5 $\mathrm{ml}$ phosphate buffer using a homogenizer (IKA Yellow line DI 18 Disperser, Germany). The homogenates were centrifuged at $6,000 \mathrm{rpm}$ for 1 hour at $4^{\circ} \mathrm{C}$ and the supernatant was kept frozen at $20^{\circ} \mathrm{C}$ for the subsequent biochemical assays. The supernatant was divided into two parts; the $1^{\text {st }}$ part was used for the measurement of lipid peroxidation (LPO) as MDA according to the method of (Ohkawa et al., 1979) and the $2^{\text {nd }}$ part was used to measure glutathione (GSH) according to the method of (Beutler et al., 1963). Blood samples were centrifuged at $4000 \mathrm{rpm}$ for $10 \mathrm{~min}$ to separate plasma and stored at $-20^{\circ} \mathrm{C}$ to be used for the determination of liver function tests.

\subsection{Determination of DNA fragmentation}

Apoptotic and damage changes in the hepatic tissue were determined calorimetrically of a known amount of DNA according to the method of (Perandones et al., 1993).

\subsection{Histopathological methods and quantification of liver fibrosis}

Pieces of liver were dissected out rapidly from the killed animals and were fixed immediately in $10 \%$ neutral buffered formalin for histopathological studies according to (Drury and Wallington, 1980). Staining by Masson's trichrome was used for the quantification of liver fibrosis (Casas-Grajales et al., 2017).

\subsection{Western blotting analysis}

The expression of P53 and NF-k $\beta$ were determined by western blot analysis according to the method of Badr et al. (2010).

\subsection{Statistical analysis}

Data were expressed as mean $\pm \mathrm{SE}$ (standard error of the mean), all results were statistical analyzed using one-way analysis of variance (ANOVA), the Tukey-HSD test was used to find if there was any significant difference between groups at $\mathrm{p}<0.05$. These analyses were performed using Statistical Package for Social Sciences (SPSS) version 16.

\section{Results}

\subsection{TAA disrupted liver morphology}

Gross examination was performed on liver specimens after anesthesia and sacrificed from each group. In control rats the liver has a regular smooth surface (Fig .1A), in TAA-treated rats the liver has a rough nodular surface (micro and macro nodules) (Fig .1B), while the rats co-treated with (TAA+QU), (TAA+EHNA) and (TAA+QU+EHNA) have a normal smooth surface and nearly normal anatomical shape and appearance compared to TAA-treated group (Fig .1C-E).
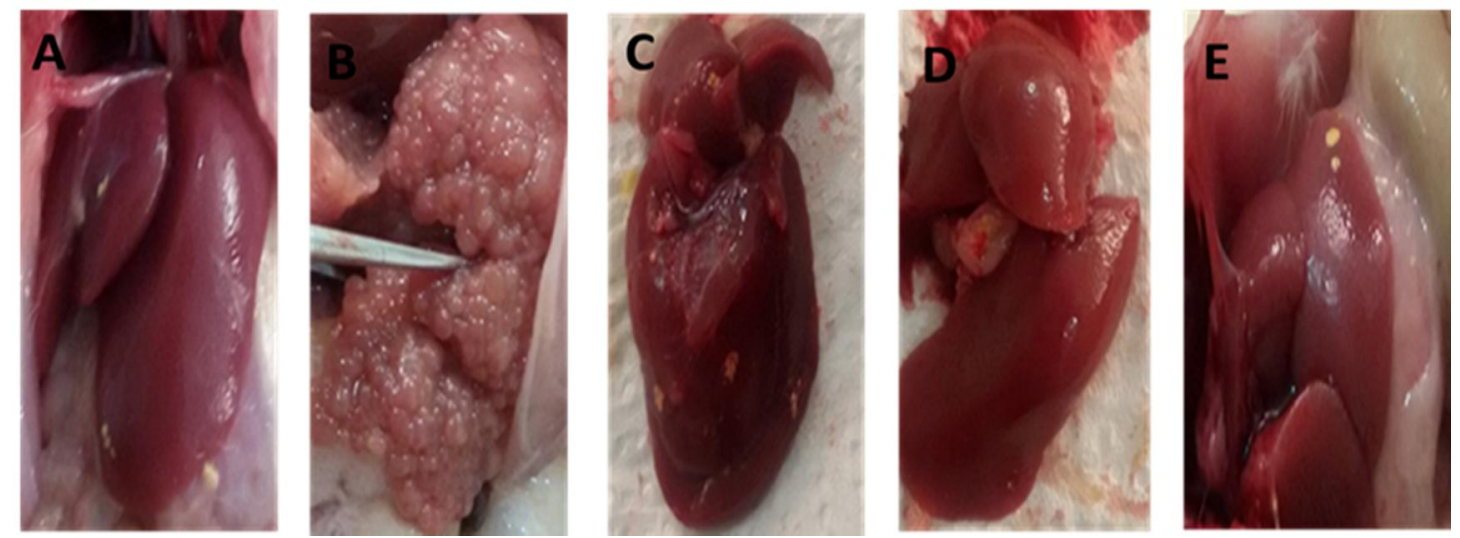

Fig. 1: Gross examination of the liver shows the effect of TAA toxicity on the liver morphology. Control group (A), TAA-treated group (B), TAA+QU group (C), TAA+EHNA group (D) and $\mathrm{TAA}+\mathrm{QU}+\mathrm{EHNA}$ group $(\mathrm{E})$. Liver shown are representative samples where $\mathrm{n}=6$. 


\subsection{Administration of quercetin and EHNA improved the liver functions tests}

As compared to control rats the level of ALT, AST, GGT activities and TB level were significantly elevated in liver of TAA-treated group. Groups of rats co-treated with QU alone or EHNA alone and the combination of both showed improvement in the ALT, AST, GGT activities and TB level in comparison to TAA-treated group but still higher than control (Table 1).

Table 1: Effect of QU and EHNA on the activities of ALT (alanine transaminase), AST (aspartate transaminase), GGT (gamma glutamic transpeptidase) and the level of TB (total bilirubin) in plasma of control and different treated groups. Results presented as mean $\pm \mathrm{SE}$, the different letters ( $a, b, c$ and $d$ ) means significant difference at $\mathrm{p}<0.05$ between different group, where $\mathrm{n}=6$.

\begin{tabular}{llllll}
\hline \multicolumn{1}{c}{ G } & Control & TAA & TAA +QU & TAA+ EHNA & TAA+QU+EHNA \\
\hline ALT (U/L) & $37.5 \pm 3.24^{\mathbf{a}}$ & $191.43 \pm 10.43^{\mathbf{c}}$ & $115.71 \pm 10.00^{\mathbf{b}}$ & $143.71 \pm 9.50^{\mathbf{b}}$ & $117.14 \pm 6.88^{\mathbf{b}}$ \\
AST (U/L) & $38.00 \pm 0.60^{\mathbf{a}}$ & $114.25 \pm 3.70^{\mathbf{d}}$ & $60.50 \pm 3.50^{\mathbf{b}}$ & $74.58 \pm 2.84^{\mathbf{c}}$ & $54.83 \pm 3.76^{\mathbf{b}}$ \\
GGT (U/L) & $2.00 \pm 0.18^{\mathbf{a}}$ & $7.33 \pm 0.43^{\mathbf{d}}$ & $4.83 \pm 0.46^{\mathbf{b c}}$ & $3.50 \pm 0.33^{\text {ab }}$ & $5.67 \pm 0.70^{\text {cd }}$ \\
TB (mg/dl) & $0.12 \pm 0.01^{\mathbf{a}}$ & $0.26 \pm 0.01^{\mathbf{d}}$ & $0.19 \pm 0.003^{\mathbf{c}}$ & $0.14 \pm 0.01^{\text {ab }}$ & $0.16 \pm 0.01^{\mathbf{b}}$ \\
\hline
\end{tabular}

\subsection{Treatment of TAA with quercetin and EHNA restored the high level of ROS and improved} the antioxidant level

As compared to control rats the GSH level was significantly decreased in the liver of TAA-treated group. On the other hand, co-treatment with QU alone, EHNA alone and combination of both caused significantly increased in GSH level in comparison to TAA-treated group, it also showed that no significant difference between the treatment with the QU alone, EHNA alone, the combination of both and control. As compared to control rats the LPO level was significantly increased in the liver of TAAtreated group. On the other hand, co-treatment with QU alone, EHNA alone and the combination of both caused significantly decreased in LPO level in comparison to TAA-treated group but still higher than control. As compared to control rats the change in DNA fragmentation was significantly increased in the liver of TAA-treated group. On the other hand, co-treatment with QU alone, EHNA alone and the combination of both caused significantly decreased in the changed of DNA fragmentation in comparison to TAA- treated group but still higher than control (Table 2).

Table 2: Effect of QU and EHNA on the level of GSH (glutathione), LPO (lipid peroxidation) and \% of change in DNA fragmentation in hepatic tissue of control and different treated groups. Results presented as mean $\pm \mathrm{SE}$, the different letters ( $\mathrm{a}, \mathrm{b}, \mathrm{c}$ and d) means significant difference at $\mathrm{p}<0.05$ between different group, where $n=6$.

\begin{tabular}{llllll}
\hline \multicolumn{1}{c}{ G } & Control & TAA & TAA+QU & TAA+EHNA & TAA+QU+EHNA \\
\hline GSH ( $\boldsymbol{\mu g} / \mathbf{m g}$ protein) & $70.50 \pm 2.06^{\mathbf{a b}}$ & $56.67 \pm 2.30^{\mathbf{d}}$ & $76.44 \pm 2.20^{\mathbf{b}}$ & $79.00 \pm 2.70^{\mathbf{b}}$ & $67.11 \pm 1.62^{\mathbf{a}}$ \\
$\begin{array}{l}\text { LPO (nmol/mg protein) } \\
\text { \% of change of DNA } \\
\text { fragmentation }\end{array}$ & $7.39 \pm 0.68^{\mathbf{a}}$ & $27.52 \pm 2.05^{\mathbf{c}}$ & $16.26 \pm 0.28^{\mathbf{b}}$ & $13.29 \pm 1.13^{\mathbf{b}}$ & $14.37 \pm 0.35^{\mathbf{b}}$ \\
\hline
\end{tabular}

\subsection{Treatment with quercetin and EHNA improved the histopathological alterations induced by TAA}

Liver of control rats showed normal architectural organization (Fig .2A). Liver of TAA-treated group showed complete loss of architectural organization with manifestations of necrosis, large fibrous septa or collagen deposition forming pseudobulbs extended from the central vein, damaged hepatic cells, hepatocytic vacuolation, scattered inflammatory cells, giant cell transformation, and biliary hyperplasia (Fig .2B), while the rats co-treated with (TAA+QU), (TAA+EHNA) and (TAA+QU+EHNA) showed marked improvement in hepatic morphology and architectural as the large fibrous septa or collagen deposition was reduced, no bridging necrosis, apoptotic and inflammatory cells were decreased compared with TAA-treated group (Fig. 2C-E). 

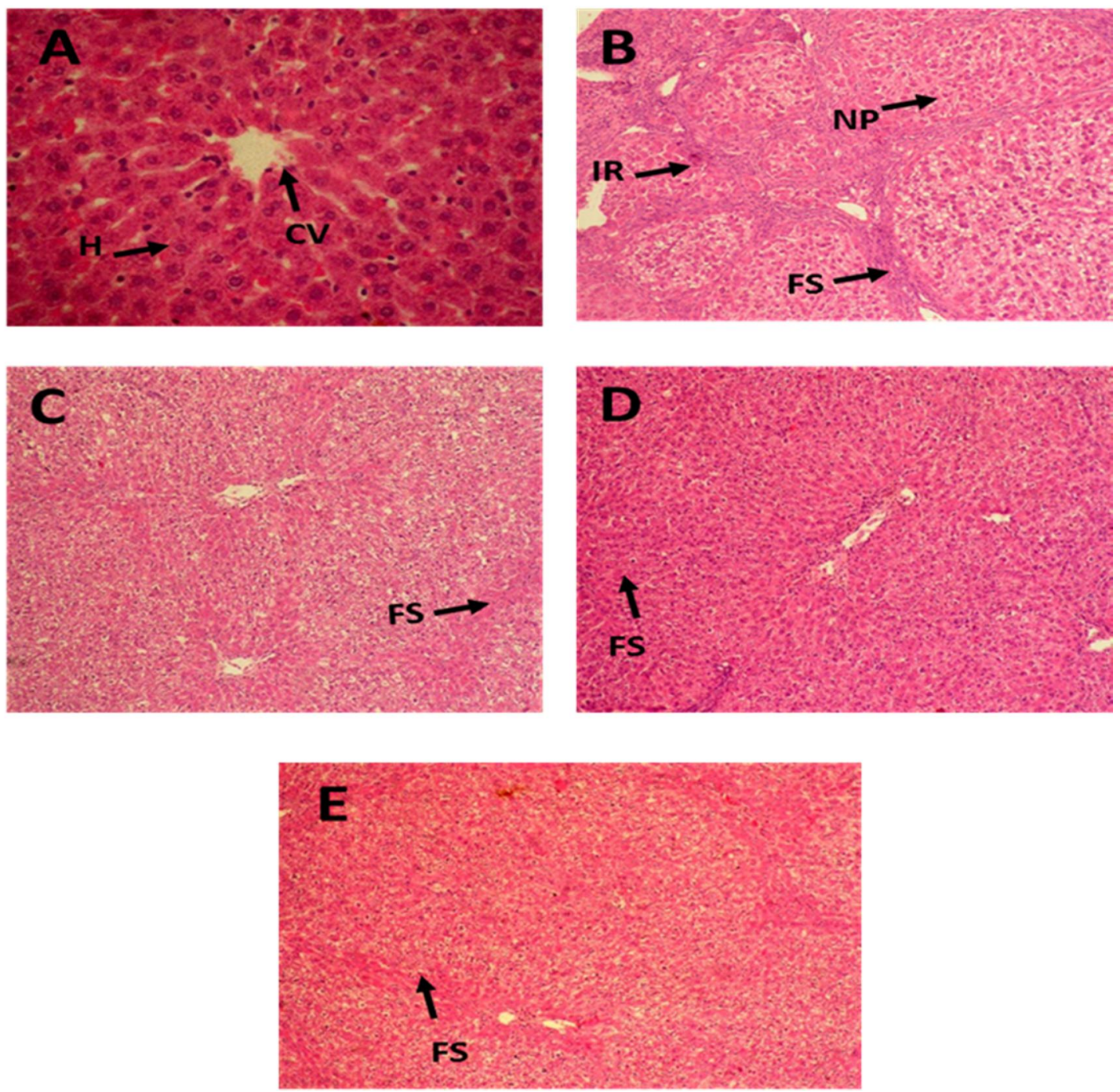

Fig. 2: Effect of QU and EHNA on hepatic changes in H\&E (X200) stained images of liver tissues of the control group (A), TAA-treated group (B), TAA+QU group (C), TAA+EHNA group (D) and TAA+QU+EHNA group (E). Abbreviation: (CV) Central Vein, (H) Hepatocyte, (FS) Fibrous Septs, (IR) Inflammation Reaction, (NP) Newly pseudo lobulation with thick fibrous septs.

\subsection{Quercetin and EHNA administration decreased liver fibrosis induced by TAA}

Liver of the control group showed no collagen deposition and normal hepatic architecture (Fig .3A). Liver of rats treated with TAA showed extended collagen deposition (arrows) from central vein and large septa forming hepatic pseudo lobules compared with the control group (Fig .3B), while the rats co-treated with (TAA+QU), (TAA+EHNA) and (TAA+QU+EHNA) showed marked reduction in collagen deposition (arrows) and in the severity of hepatic fibrosis compared with TAA-treated group (Fig .3C-E).

\subsection{The upregulation of the inflammatory and apoptotic markers induced by TAA were restored in quercetin and EHNA treated groups}

We measured the expression of P53 as an apoptotic marker and NF-k $\beta$ as an inflammation marker by Western blot analysis. In normal hepatic tissue, the expression of P53 and NF-k $\beta$ were very weak (Fig. 4A). In the hepatic tissue of TAA-treated group there were a significant increase in P53 and NF$\mathrm{k} \beta$ expression compared with the control group (Fig .4B). On the other hand, in hepatic tissue of TAA+QU group (Fig .4C), TAA+EHNA group (Fig .4D), and TAA+QU+EHNA group (Fig .4E), the expression of P53 and NF-k $\beta$ were significantly decreased in comparison to TAA-treated group but it also showed that treatment with the combination of QU and EHNA gave a better result than treatment with QU alone and EHNA alone. 

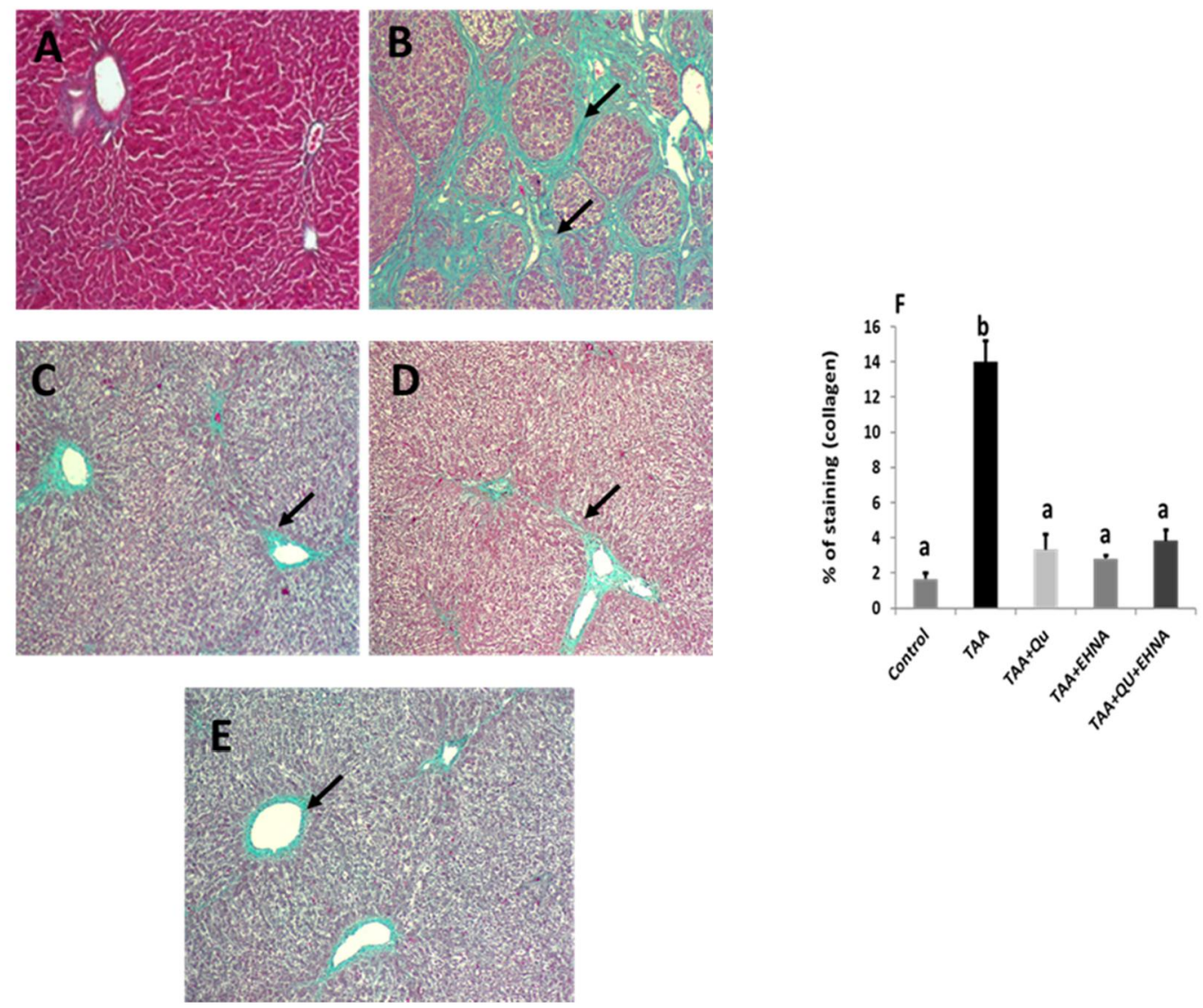

Fig. 3: Effect of QU and EHNA on hepatic changes in Masson's trichrome (X100) stained images of liver tissues of the control group (A), TAA-treated group (B), TAA+QU group (C), TAA+EHNA group (D) and TAA+QU+EHNA group (E). Quantitative analysis of Masson's trichrome staining as mean $\pm \mathrm{SE}$ in liver tissue of control and different treated rats $(\mathrm{F})$, the different letters $(a$ and $b$ ) means significant difference at $p<0.05$ between different group, where $\mathrm{n}=6$.

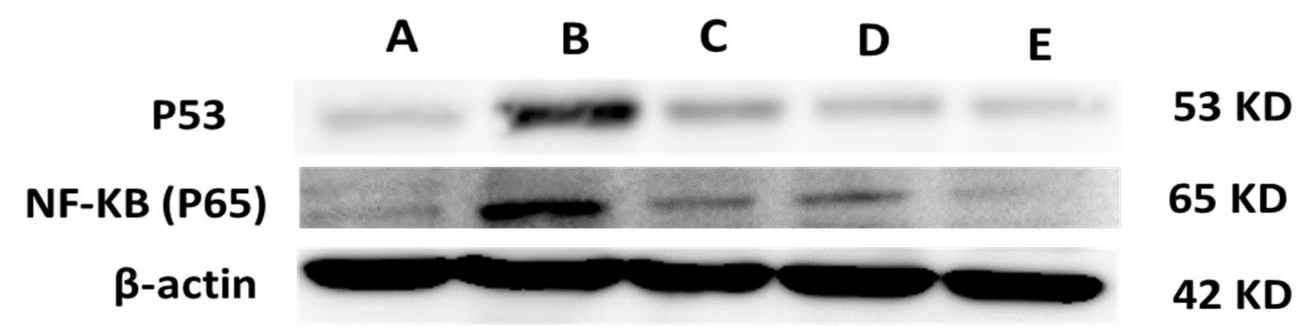

Fig. 4: Western blot analysis of P53 and NF-k $\beta$. Labeling is demonstrated in the control group (A), TAA-treated group (B), TAA+QU group (C), TAA+EHNA group (D) and TAA+QU+EHNA group (E), the expression levels of P53 and NF-k $\beta$ were normalized to those of $\beta$-actin in all groups

\section{Discussion}

Liver plays various roles in the metabolism of different nutrients, clearance of waste products and regulating physiological processes, on the other hand, liver diseases have become the major causes of deaths all over the world (Saleem et al., 2010; Zargar et al., 2017). TAA considered as strongly hepatotoxic compound could cause damage in liver that lead to the release of inflammatory cells, activation of Kupffer and hepatic stellate cells (HSC) which transdifferentiate into myofibroblast-like cells, secrete extracellular matrix proteins (ECM) and release of cytokines, growth factors and reactive oxygen species (ROS) (Kubo et al., 2016; Thuy le et al., 2017). 
Our results showed that the administration of TAA $(200 \mathrm{mg} / \mathrm{kg} \mathrm{BW})$ induced significantly elevated in the activities of liver enzymes ALT, AST, GGT and TB level. This elevation due to marked hepatic membrane damage (Bansal et al., 2005) or may be due to the possible effect of tumor on liver tissues leading to release of this enzymes into the blood (Abdo et al., 2015). The GGT enzyme is used as a tumor marker (Carrasco-Torres et al., 2017), so it has been analyzed for the identification of preneoplastic cells (Dragan and Pitot, 1992; Hanigan, 1998). Furthermore, the elevation of plasma TB level in the TAA group may be due to blockage of bile ducts so the secretion of TB was decreased from the liver (Afifi et al., 2016). The decrease of the plasma enzymes AST, ALT, GGT and TB level in rats co-treated with QU alone, EHNA alone and the combination of both due to they have the ability to reduce hepatic damage, helped in hepatocyte regeneration, and maintained cell membrane stabilization/integrity, therefore suppressed the release of this enzymes into the blood (Medhat et al., 2017). Also, EHNA elevated endogenous adenosine concentrations which could provide the binding to $\left(\mathrm{A}_{2 \mathrm{~A}}\right.$ adenosine receptor) results in anti-inflammatory effects, so the neutrophil decreased the ROS and reduced the hepatic membrane damage (Cavalcante et al., 2006).

Injection by TAA significantly elevated liver MDA content reflecting increased lipid peroxidation duo to damage of the liver and also due to formation of excessive ROS (Aly et al., 2019). Also, significantly decreased in the GSH level may be due to the generation of ROS from metabolism of TAA and suppressed antioxidant defense mechanism (Zargar et al., 2015). In QU alone, EHNA alone and the combination of both, the LPO level was decreased because the inhibition of ADA with EHNA reduced free radical generation (Xia et al., 1996), also due to strong inhibitory effects of QU on CytP2E1 and a Cyt-P450 isoforms (Ryu et al., 2016), but in the groups of QU alone, EHNA alone and the combination of both the hepatic GSH level was elevated may be due to that the QU and EHNA suppressed the level of LPO and the formation of ROS then restoration of the antioxidant system of the liver (Sathya et al., 2014).

DNA fragmentation is as characteristic feature of apoptosis (Elmore, 2007). In TAA-treated group the change in DNA fragmentation was significantly increased supported by histopathological study. This increase may be due to increase the level of ROS that cause DNA damage and cell death via both apoptosis and necrosis (Chen et al., 2006). Co- treatment with QU alone, EHNA alone and the combination of both decreased the change in DNA fragmentation because they could reduce hepatocytes damage and decrease ROS-mediated DNA damage (Shalaby and Saleh, 2011).

In TAA-treated rats the histopathological features showed severe liver cell damage in rats supporting the observed changes in biochemical assays, histological examination showed complete loss of architectural and centrilobular necrosis (Afifi et al., 2016). Our results are in agreement with (Yogalakshmi et al., 2010) that showed a large number of inflammatory and apoptotic cells with increased collagen fibers which lead to form pseudo lobules, also fatty degenerated and vacuolation in hepatocytes were observed ( $\mathrm{Li}$ et al., 2014). Those observation are in agreement with Talluri et al. (2016) and Miguel et al. (2017) who reported that TAA induced hepatic damage and production of oxidative stress. After treatment with QU alone, EHNA alone and the combination of both the histological features was improved as reformed in architecture organization, decreased necrosis, apoptosis, inflammatory cells and the deposition of collagen fibers, these data are consistent with other studies of cirrhosis that used substances with antioxidant power such as silymarin (Tsai et al., 2008) and curcumin (Bengmark et al., 2009).

The P53 plays an important role in cell cycle regulation, DNA repair and apoptosis (Ali et al., 2019). In TAA-treated rats the P53 expression was significantly upregulated this may be due to gene products modulate biochemical pathways that regulate cells apoptosis and proliferation, these results came in accordance with Kartik et al. (2010) who reported that P53 expression was increased after TAA administration. Deregulation of signaling pathways during the development of $\mathrm{HCC}$ affects normal cellular processes such as cell cycle and apoptosis (Mukherjee, 2009). Somatic mutations in P53 gene are the most common genetic defects in human cancer and supports a high level of P53 expression in fibrosis and HCC (Gomaa et al., 2008). Our studies showed that co-treatment with QU alone, EHNA alone and the combination of both significantly downregulated the expression of P53 due to QU and EHNA have the ability to reduce hepatocyte damage and apoptosis and decrease the formation of ROSmediated DNA damage (Shalaby and Saleh, 2011). 
NF-k $\beta$ transcriptionally regulates a large number of genes which have inflammatory effects (Ubeda et al., 2013). In TAA-intoxicated group showed a significant upregulated in NF-k $\beta$ expression due to the formation of the reactive metabolite of TAA that expresses proinflammatory molecules (Bahcecioglu et al., 2015). Also, by regulating hepatocyte, HSC, and Kupffer cell functions the NF-k $\beta$ activation is involved in the liver fibrosis (Bataller and Brenner, 2005). Treatment with QU alone, EHNA alone and the combination of both significantly downregulated the expression of NF-k $\beta$ due to QU could maintain NF-k $\beta$ in an inactive form and reduce the inflammatory cytokines through the inhibition of specific receptors (Toll-like receptor 2 (TLR2) and the Toll-like receptor 4 (TLR4)) (Ma et al., 2015), and EHNA elevated endogenous adenosine concentrations which could provide the binding to (A2A and A2B) adenosine receptors results in anti-inflammatory effects, like the decrease neutrophil inflammatory functions (Sands et al., 2004).

\section{Conclusion}

The data obtained suggest that any of QU alone, EHNA alone or the combination of both can protect against liver fibrosis by suppression of P53 and NF-k $\beta$ gene expression due to their antiinflammatory, antioxidant, and anti-apoptotic activities. According to our results, after more experimental and trials, QU alone, EHNA alone or the combination of both can be used to prevent the liver against TAA toxicity.

\section{References}

Abdo, W., A. Hirata, M. Shukry, T. Kamal, E. Abdel-Sattar, E. Mahrous, and T. Yanai, 2015. Calligonum comosum extract inhibits diethylnitrosamine-induced hepatocarcinogenesis in rats. Oncol. Lett., 10: 716-722.

Afifi, N., A. Ramadana, W. El-Erakyb, A. Salama, A. El-Fadalyb, and A. Hassanc, 2016. Quercetin protects against thioacetamide induced hepatotoxicity in rats through decreased oxidative stress

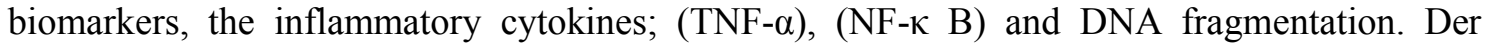
Pharma Chemica, 8: 48-55.

Aly, S.M., H.A. Fetaih, A.A.I. Hassanin, M.M. Abomughaid, and A.A. Ismail, 2019. Protective Effects of Garlic and Cinnamon Oils on Hepatocellular Carcinoma in Albino Rats. Analytical cellular pathology (Amsterdam) 9895485.

Amali, A.A., R.D. Rekha, C.J. Lin, W.L. Wang, H.Y. Gong, G.M. Her, and J.L. Wu, 2006. Thioacetamide induced liver damage in zebrafish embryo as a disease model for steatohepatitis. J. Biomed. Sci., 13: 225-232.

Badr, G., H. Waly, H.M. Eldien, H. Abdel-Tawab, K. Hassan, I.M. Alhazza, H. Ebaid, and S.H. Alwasel, 2010. Blocking type I interferon (IFN) signaling impairs antigen responsiveness of circulating lymphocytes and alters their homing to lymphoid organs: protective role of type I IFN. Cell Physiol. Biochem., 26: 1029-1040.

Bahcecioglu, I.H., M. Ispiroglu, M. Tuzcu, C. Orhan, M. Ulas, U. Demirel, M. Yalniz, I.H. Ozercan, N. Ilhan, and K. Sahin, 2015. Pistacia Terebinthus Coffee Protects against ThioacetamideInduced Liver Injury in Rats. Acta Medica (Hradec Kralove) 58: 56-61.

Bansal, A.K., M. Bansal, G. Soni, and D. Bhatnagar, 2005. Protective role of Vitamin E pre-treatment on N-nitrosodiethylamine induced oxidative stress in rat liver. Chem Biol Interact, 156: 101-111.

Barankiewicz, J., A.M. Danks, E. Abushanab, L. Makings, T. Wiemann, R.A. Wallis, P.V. Pragnacharyulu, A. Fox, and P.J. Marangos, 1997. Regulation of adenosine concentration and cytoprotective effects of novel reversible adenosine deaminase inhibitors. J. Pharmacol. Exp. Ther., 283: 1230-1238.

Barreca, D., E. Bellocco, G. D'Onofrio, S.F. Nabavi, M. Daglia, L. Rastrelli, and S.M. Nabavi, 2016. Neuroprotective Effects of Quercetin: From Chemistry to Medicine. CNS Neurol Disord Drug Targets 15, 964-975. Bataller, R., Brenner, D.A., 2005. Liver fibrosis. J. Clin. Invest., 115: 209218.

Bengmark, S., M.D. Mesa, and A. Gil, 2009. Plant-derived health: the effects of turmeric and curcuminoids. Nutr. Hosp., 24: 273-281. 
Beutler, E., O. Duron, and B.M. Kelly, 1963. Improved method for the determination of blood glutathione. J. Lab. Clin. Med., 61: 882-888.

Carrasco-Torres, G., H.C. Monroy-Ramirez, A.A. Martinez-Guerra, R. Baltierrez-Hoyos, M.L.A. Romero-Tlalolini, S. Villa-Trevino, X. Sanchez-Chino, and V.R. Vasquez-Garzon, 2017. Quercetin Reverses Rat Liver Preneoplastic Lesions Induced by Chemical Carcinogenesis. Oxid Med Cell Longev, 4674918.

Casas-Grajales, S., and P. Muriel, 2015. Antioxidants in liver health. World J Gastrointest Pharmacol. Ther., 6: 59-72.

Casas-Grajales, S., L.F. Vázquez-Flores, E. Ramos-Tovar, E. Hernández-Aquino, R.E. Flores-Beltrán, C.M. Cerda-García-Rojas, J. Camacho, M. Shibayama, V. Tsutsumi, and P. Muriel, 2017. Quercetin reverses experimental cirrhosis by immunomodulation of the proinflammatory and profibrotic processes. Fundamental \& clinical pharmacology, 31: 610-624.

Cavalcante, I.C., M.V. Castro, A.R. Barreto, G.W. Sullivan, M. Vale, P.R. Almeida, J. Linden, J.M. Rieger, F.Q. Cunha, R.L. Guerrant, R.A. Ribeiro, and G.A. Brito, 2006. Effect of novel A2A adenosine receptor agonist ATL 313 on Clostridium difficile toxin A-induced murine ileal enteritis. Infect. Immun., 74: 2606-2612.

Chen, L.H., C.Y. Hsu, C. Weng, L.H. Chen, C.Y. Hsu, and C.F. Weng, 2006. Involvement of P53 and Bax/Bad triggering apoptosis in thioacetamide-induced hepatic epithelial cells. World $\mathrm{J}$ Gastroenterol 12: 5175-5181. World journal of gastroenterology : WJG 12: 5175-5181.

Chen, T.M., Y.M. Subeq, R.P. Lee, T.W. Chiou, and B.G. Hsu, 2008. Single dose intravenous thioacetamide administration as a model of acute liver damage in rats. Int. J. Exp. Pathol., 89: 223-231.

De Minicis, S., T. Kisseleva, H. Francis, G.S. Baroni, A. Benedetti, D. Brenner, D. Alvaro, G. Alpini, and M. Marzioni, 2013. Liver carcinogenesis: rodent models of hepatocarcinoma and cholangiocarcinoma. Dig Liver Dis., 45: 450-459.

Dragan, Y.P., and H.C. Pitot, 1992. The role of the stages of initiation and promotion in phenotypic diversity during hepatocarcinogenesis in the rat. Carcinogenesis, 13: 739-750

Drury and Wallington, 1980. Carletons histological technique

Eid, H.M., and P.S. Haddad, 2017. The Antidiabetic Potential of Quercetin: Underlying Mechanisms. Curr. Med. Chem., 24: 355-364.

Elmore, S., 2007. Apoptosis: a review of programmed cell death. Toxicol Pathol 35, 495-516.

El-Nekeety, A.A., S.H. Abdel-Azeim, A.M. Hassan, N.S. Hassan, S.E. Aly, and M.A. Abdel-Wahhab, 2014. Quercetin inhibits the cytotoxicity and oxidative stress in liver of rats fed aflatoxincontaminated diet. Toxicology Reports, 1: 319-329.

Fredholm, B.B., A.P. IJzerman, K.A. Jacobson, K.-N. Klotz, and J. Linden, 2001. International Union of Pharmacology. XXV. Nomenclature and Classification of Adenosine Receptors. Pharmacological Reviews, 53: 527-552.

Friedman, S.L., 2000. Molecular regulation of hepatic fibrosis, an integrated cellular response to tissue injury. J. Biol. Chem., 275: 2247-2250.

Gomaa, A.I., S.A. Khan, M.B. Toledano, I. Waked, and S.D. Taylor-Robinson, 2008. Hepatocellular carcinoma: epidemiology, risk factors and pathogenesis. World J Gastroenterol, 14: 4300-4308.

Granado-Serrano, A.B., M.A. Martin, L. Bravo, L. Goya, S. Ramos, 2012. Quercetin attenuates TNFinduced inflammation in hepatic cells by inhibiting the NF-kappaB pathway. Nutr Cancer, 64: 588-598.

Gupta, N.K., and V.K. Dixit, 2009. Hepatoprotective activity of Cleome viscosa Linn. extract against thioacetamide-induced hepatotoxicity in rats. Nat. Prod. Res., 23: 1289-1297

Hanigan, M.H., 1998. gamma-Glutamyl transpeptidase, a glutathionase: its expression and function in carcinogenesis. Chem. Biol. Interact., 111-112:333-342.

Hasko, G., and B.N. Cronstein, 2004. Adenosine: an endogenous regulator of innate immunity. Trends Immunol., 25: 33-39.

Junqueira, A.F.T.d.A., A.M. Dias, M.L. Vale, G.M.G.T. Spilborghs, A. Bossa, B.B. Lima, A.F. Carvalho, R. Guerrant, R. Ribeiro, and G.A. Brito, 2010. Adenosine Deaminase Inhibition Prevents Clostridium difficile Toxin A-Induced Enteritis in Mice. Infection and Immunity, 79: 653-662. 
Kadir, F.A., F. Othman, M.A. Abdulla, F. Hussan, and P. Hassandarvish, 2011. Effect of Tinospora crispa on thioacetamide-induced liver cirrhosis in rats. Indian J. Pharmacol., 43: 64-68.

Kartik, R., C. Venkateshwara Raoa, P. Pushpangadan, S.P. Trivedi, and G.D. Reddy, 2010. Exploring the Protective Effects of Abrus precatorius in HepG2 and N-Nitrosodiethylamine-Induced Hepatocellular Carcinoma in Swiss Albino Rats. Iranian Journal of Pharmaceutical Sciences, 6: 99-114.

Kaur, V., M. Kumar, P. Kaur, S. Kaur, A.P. Singh, and S. Kaur, 2017. Hepatoprotective activity of Butea monosperma bark against thioacetamide-induced liver injury in rats. Biomed Pharmacother, 89: 332-341.

Kubo, N., K. Araki, H. Kuwano, and K. Shirabe, 2016. Cancer-associated fibroblasts in hepatocellular carcinoma. World J. Gastroenterol, 22: 6841-6850.

Lee, J.W., K.D. Shin, M. Lee, E.J. Kim, S.S. Han, M.Y. Han, H. Ha, T.C. Jeong, and W.S. Koh, 2003. Role of metabolism by flavin-containing monooxygenase in thioacetamide-induced immunosuppression. Toxicol Lett., 136: 163-172.

Li, S., H.Y. Tan, N. Wang, Z.J. Zhang, L. Lao, C.W. Wong, and Y. Feng, 2015. The Role of Oxidative Stress and Antioxidants in Liver Diseases. International journal of molecular sciences, 16: 2608726124.

Li, W., C. Zhu, Y. Li, Q. Wu, and R. Gao, 2014. Mest attenuates CCl4-induced liver fibrosis in rats by inhibiting the Wnt/beta-catenin signaling pathway. Gut. Liver, 8: 282-291.

Luo, M., L. Dong, J. Li, Y. Wang, B. Shang, 2015. Protective effects of pentoxifylline on acute liver injury induced by thioacetamide in rats. Int. J. Clin. Exp. Pathol., 8:8990-8996.

Lupidi, G., F. Marmocchi, G. Venardi, and G. Cristalli, 1997. Functional residues at the active site of bovine brain adenosine deaminase. Biochem. Mol. Biol. Int., 43, 1339-1352.

Ma, J.Q., Z. Li, W.R. Xie, C.M. Liu, and S.S. Liu, 2015. Quercetin protects mouse liver against $\mathrm{CCl}_{4}$ induced inflammation by the TLR2/4 and MAPK/NF- $\mathrm{KB}$ pathway. International immunopharmacology, 28: 531-539.

Madhavan, S., M. Anghelina, B. Rath-Deschner, E. Wypasek, A. John, J. Deschner, N. Piesco, and S. Agarwal, 2006. Biomechanical signals exert sustained attenuation of proinflammatory gene induction in articular chondrocytes. Osteoarthritis Cartilage, 14: 1023-1032.

Manach, C., O. Texier, C. Morand, V. Crespy, F. Regerat, C. Demigne, and C. Remesy, 1999. Comparison of the bioavailability of quercetin and catechin in rats. Free Radic Biol. Med., 27: 1259-1266.

Massi, A., O. Bortolini, D. Ragno, T. Bernardi, G. Sacchetti, M. Tacchini, and C. De Risi, 2017. Research Progress in the Modification of Quercetin Leading to Anticancer Agents. Molecules (Basel, Switzerland) 22.

Medhat, A., S. Mansour, S. El-Sonbaty, E. Kandil, and M. Mahmoud, 2017. Evaluation of the antitumor activity of platinum nanoparticles in the treatment of hepatocellular carcinoma induced in rats. Tumour. Biol., 39: 1010428317717259.

Miguel, F.M., E.G. Schemitt, J.R. Colares, R.M. Hartmann, M.I. Morgan-Martins, and N.P. Marroni, 2017. Action of Vitamin E on Experimental Severe Acute Liver Failure. Arq Gastroenterol, 54: 123-129.

Mukherjee, 2009. Chemically induced hepatocellular carcinoma and stages of development with biochemical and genetic modulation. Indian Council of Medical Research, 58: 201-219.

Nakajima, Y., T. Kanno, T. Nagaya, K. Kuribayashi, T. Nakano, A. Gotoh, and T. Nishizaki, 2015. Adenosine deaminase inhibitor EHNA exhibits a potent anticancer effect against malignant pleural mesothelioma. Cell Physiol. Biochem., 35: 51-60.

Nazmy, E.A., O.A. El-Khouly, M.M.A. Zaki, N.M. Elsherbiny, E. Said, M.M.H. Al-Gayyar, and H.A. Salem, 2019. Targeting p53/TRAIL/caspase- 8 signaling by adiponectin reverses thioacetamideinduced hepatocellular carcinoma in rats. Environ. Toxicol Pharmacol., 72: 103240.

Ohkawa, H., N. Ohishi, and K. Yagi, 1979. Assay for lipid peroxides in animal tissues by thiobarbituric acid reaction. Anal. Biochem., 95: 351-358.

Perandones, C.E., V.A. Illera, D. Peckham, L.L. Stunz, and R.F.Ashman, 1993. Regulation of apoptosis in vitro in mature murine spleen T cells. J. Immunol., 151:3521-3529. 
Prabha, S.P., P.N. Ansil, A. Nitha, P.J. Wills, and M.S. Latha, 2012. Preventive and curative effect of methanolic extract of Gardenia gummifera Linn. f. on thioacetamide induced oxidative stress in rats. Asian Pacific Journal of Tropical Disease, 2: 90-98

Ryu, C.S., S.J. Oh, J.M. Oh, J.Y. Lee, S.Y. Lee, J.W. Chae, K.I. Kwon, and S.K. Kim, 2016. Inhibition of Cytochrome P450 by Propolis in Human Liver Microsomes. Toxicol. Res., 32: 207-213

Saleem, T.M., C.M. Chetty, S. Ramkanth, V. Rajan, K.M. Kumar, and K. Gauthaman, 2010. Hepatoprotective Herbs A Review. International Journal of Research in Pharmaceutical Sciences, 1: $1-5$.

Sands, W.A., A.F. Martin, E.W. Strong, and T.M. Palmer, 2004. Specific inhibition of nuclear factorkappaB-dependent inflammatory responses by cell type-specific mechanisms upon A2A adenosine receptor gene transfer. Mol. Pharmacol., 66: 1147-1159.

Sathya, M., V. Rajeshwari, and K. Sakthishree, 2014. Influence of aqueous extract of Cinnamomum zeylanicum on the progression of cancer in diethylnitrosamine induced rat liver,. European Journal of Experimental Biology, 4: 190-195.

Sauer, A.V., I. Brigida, N. Carriglio, and A. Aiuti, 2012. Autoimmune dysregulation and purine metabolism in adenosine deaminase deficiency. Front Immunol., 3: 265.

Seki, E., S. De Minicis, G.Y. Gwak, J. Kluwe, S. Inokuchi, C.A. Bursill, J.M. Llovet, D.A. Brenner, and R.F.Schwabe, 2009. CCR1 and CCR5 promote hepatic fibrosis in mice. J. Clin. Invest., 119: 1858-1870.

Shalaby, K., and E. Saleh, 2011. Ameliorative Effect of Honey Bee Propolis on the Nonylphenol Induced-Reproductive Toxicity in Male Albino Rats. Australian Journal of Basic and Applied Sciences, 5.

Talluri, M.R., R.S. Tadi, and G.R. Battu, 2016. Thioacetamide-induced acute liver toxicity in rats treated with Balanites roxburghii extracts. Journal of Acute Disease, 5: 413-418.

Thuy le, T.T., T.T.V. Thuy, H. Hai, and N. Kawada, 2017. Chapter 16 - Role of Oxidative and Nitrosative Stress in Hepatic Fibrosis, in: Muriel, P. (Ed.), Liver Pathophysiology. Academic Press, Boston, 213-224.

Tieppo, J., M.J. Cuevas, R. Vercelino, M.J. Tunon, N.P. Marroni, and J. Gonzalez-Gallego, 2009. Quercetin administration ameliorates pulmonary complications of cirrhosis in rats. J. Nutr., 139: 1339-1346.

Tsai, J.H., J.Y. Liu, T.T. Wu, P.C. Ho, C.Y. Huang, J.C. Shyu, Y.S. Hsieh, C.C. Tsai, and Y.C. Liu, 2008. Effects of silymarin on the resolution of liver fibrosis induced by carbon tetrachloride in rats. J. Viral. Hepat., 15: 508-514.

Ubeda, M., M. Lario, L. Munoz, D. Diaz, M.J. Borrero, L. Garcia-Bermejo, M. Alvarez-Mon, and A. Albillos, 2013. Systemic inflammation in absence of gut bacterial translocation in C57BL/6 mice with cirrhosis. Gut., 62: 330-331.

Wu, L.C., I.W. Lu, C.F. Chung, H.Y. Wu, and Y.T. Liu, 2011. Antiproliferative mechanisms of quercetin in rat activated hepatic stellate cells. Food Funct., 2: 204-212.

Xia, Y., G. Khatchikian, and J.L. Zweier, 1996. Adenosine deaminase inhibition prevents free radicalmediated injury in the postischemic heart. J. Biol. Chem., 271: 10096-10102.

Yogalakshmi, B., P. Viswanathan, C.V. Anuradha, 2010. Investigation of antioxidant, antiinflammatory and DNA-protective properties of eugenol in thioacetamide-induced liver injury in rats. Toxicology, 268: 204-212.

Zargar, S., N.J. Siddiqi, S.K. Al Daihan, and T.A. Wani, 2015. Protective effects of quercetin on cadmium fluoride induced oxidative stress at different intervals of time in mouse liver. Acta. Biochim. Pol., 62: 207-213.

Zargar, S., T.A. Wani, A.A. Alamro, and M.A. Ganaie, 2017. Amelioration of thioacetamide-induced liver toxicity in Wistar rats by rutin. Int. J. Immunopathol Pharmacol., 30: 207-214. 